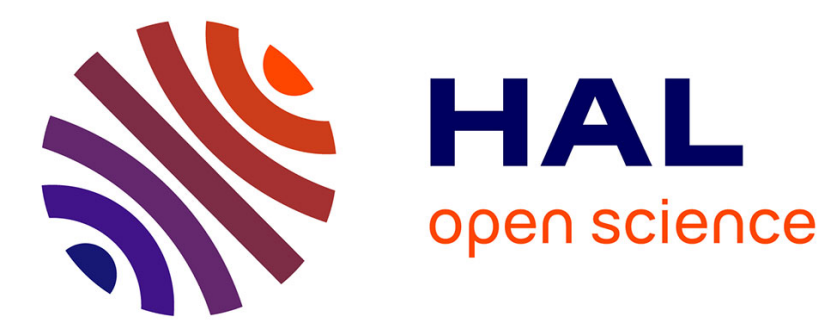

\title{
11 $\beta$-Hydroxysteroid Dehydrogenase Type 1 Inhibitors with Oleanan and Ursan Scaffolds
}

\author{
Andreas Blum, Angelo D. Favia, Edmund Maser
}

\section{To cite this version:}

Andreas Blum, Angelo D. Favia, Edmund Maser. 11 $\beta$-Hydroxysteroid Dehydrogenase Type 1 Inhibitors with Oleanan and Ursan Scaffolds. Molecular and Cellular Endocrinology, 2009, 301 (1-2), pp.132. 10.1016/j.mce.2008.08.028 . hal-00532070

\section{HAL Id: hal-00532070 \\ https://hal.science/hal-00532070}

Submitted on 4 Nov 2010

HAL is a multi-disciplinary open access archive for the deposit and dissemination of scientific research documents, whether they are published or not. The documents may come from teaching and research institutions in France or abroad, or from public or private research centers.
L'archive ouverte pluridisciplinaire HAL, est destinée au dépôt et à la diffusion de documents scientifiques de niveau recherche, publiés ou non, émanant des établissements d'enseignement et de recherche français ou étrangers, des laboratoires publics ou privés. 


\section{Accepted Manuscript}

Title: $11 \beta$-Hydroxysteroid Dehydrogenase Type 1 Inhibitors with Oleanan and Ursan Scaffolds

Authors: Andreas Blum, Angelo D. Favia, Edmund Maser

PII: $\quad$ S0303-7207(08)00387-0

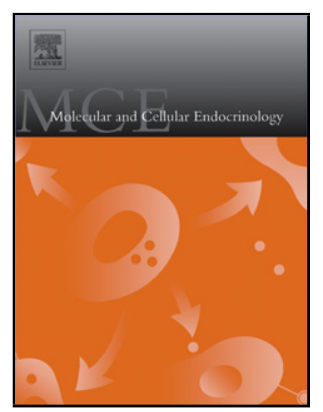

DOI: doi:10.1016/j.mce.2008.08.028

Reference: MCE 6960

To appear in: Molecular and Cellular Endocrinology

Received date: 25-6-2008

Revised date: $15-8-2008$

Accepted date: 25-8-2008

Please cite this article as: Blum, A., Favia, A.D., Maser, E., 11ß-Hydroxysteroid Dehydrogenase Type 1 Inhibitors with Oleanan and Ursan Scaffolds, Molecular and Cellular Endocrinology (2007), doi:10.1016/j.mce.2008.08.028

This is a PDF file of an unedited manuscript that has been accepted for publication. As a service to our customers we are providing this early version of the manuscript. The manuscript will undergo copyediting, typesetting, and review of the resulting proof before it is published in its final form. Please note that during the production process errors may be discovered which could affect the content, and all legal disclaimers that apply to the journal pertain. 


\title{
11ß-HYDROXYSTEROID DEHYDROGENASE TYPE 1 INHIBITORS WITH OLEANAN AND URSAN SCAFFOLDS
}

\author{
Andreas Blum ${ }^{1}$, Angelo D. Favia ${ }^{2}$ and Edmund Maser ${ }^{1}$ \\ ${ }^{1}$ Institute of Toxicology and Pharmacology for Natural Scientists, University Medical School \\ Schleswig-Holstein, Kiel, Germany. \\ ${ }^{2}$ European Molecular Biology Laboratory-European Bioinformatics Institute, Wellcome \\ Trust Genome Campus, Hinxton, Cambridge CB10 1SD, UK.
}

Keywords: 11ß-Hydroxysteroid dehydrogenase; Glucocorticoid metabolism; Metabolic syndrome; Obesity; Diabetes.

* Corresponding author. Phone: +49-431-597-3540; Fax: +49-431-597-3558

E-mail address: maser@toxi.uni-kiel.de 


\begin{abstract}

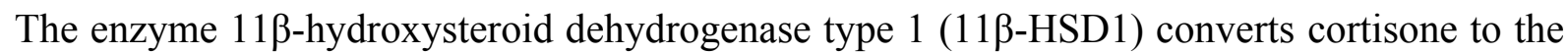
active glucocorticoid cortisol, thereby acting as a cellular switch to mediate glucocorticoid action in many tissues. Several studies have indicated that $11 \beta$-HSD1 plays a crucial role in the onset of type 2 diabetes and central obesity. As a consequence, selective inhibition of $11 \beta-$ HSD1 in humans might become a new and promising approach for lowering blood glucose concentrations and for counteracting the accumulation of visceral fat and its related metabolic abnormalities in type 2 diabetes. In this study, we present the synthesis and the biological evaluation of ursan or oleanan type triterpenoids which may act as selective 11ß-HSD1 inhibitors in liver as well as in peripheral tissues, like adipocytes and muscle cells. In order to rationalise the outcomes of the inhibition data, docking simulations of the ligands were performed on the experimentally determined structure of 11ß-HSD1. Furthermore, we discuss the structural determinants that confer enzymatic specificity. From our investigation, valuable information has been obtained to design selective 11ß-HSD1 blockers based on the oleanan and ursan scaffold.
\end{abstract}

\title{
1. Introduction
}

In humans, the ratio of active/inactive glucocorticoids is controlled by two enzyme isoforms:

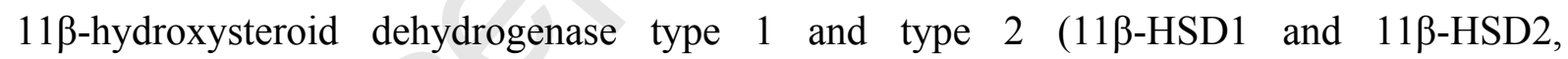
respectively) (Seckl, 2004). 11ß-HSD1 converts cortisone to the active glucocorticoid cortisol, thereby controlling access of glucocorticoid hormones to the glucocorticoid receptor (Seck1, 2004). Overexpression of $11 \beta$-HSD1 has been shown to play a crucial role in the onset of type 2 diabetes, and rodent models support the hypothesis that it might also be involved in the development of central obesity (Livingstone et al., 2000; Masuzaki et al., 2001; Liu et al., 2003). 11ß-HSD1 deficient mice show enhanced glucose tolerance, attenuated gluconeogenic responses and improved lipid and lipoprotein profiles (Kotelevtsev et al., 1997; Morton et al.,

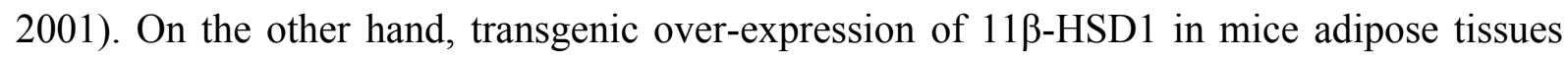
causes visceral obesity, insulin resistance, diabetes, dyslipidemia and hypertension (Masuzaki et al., 2001; Masuzaki et al., 2003). All these data suggest that selective inhibition of human 11ß-HSD1 might become a new and promising approach for lowering blood glucose 
concentrations and for counteracting the accumulation of visceral fat and its related metabolic abnormalities in type 2 diabetes (reviewed in: (Hughes et al., 2008)).

Triterpenoids like carbenoxolone, dexamethasone or glycyrrhetinic acid are non-selective inhibitors of $11 \beta$-HSD since they also inhibit $11 \beta$-HSD2, the second isoform (Stewart et al., 1987; Walker et al., 1995). 11ß-HSD2 acts as a dehydrogenase by converting active cortisol into inactive cortisone, thereby preventing inappropriate mineralocorticoid receptor activation by glucocorticoids in aldosterone target tissues. Non-selective inhibition of $11 \beta$-HSD2 results in serious side-effects like sodium retention, hypokalaemia and hypertension (Sandeep et al., 2004).

Pentacyclic triterpenes of the ursan and oleanan type are widespread in the plant kingdom and many of them have been described as physiological active compounds (Yoshikawa et al., 1997; Shimizu et al., 1997; Kim et al., 1998; Murakami et al., 2001) (Fig. 1). Clinical interests in ursan and oleanan type triterpenes relate to their anti-inflammatory, hypoglycemic, anti-virial and apoptosis inducing properties. As indicated above, $18 \beta$-glycyrrhetinic acid, a compound with an oleanan scaffold, is known as strong inhibitor of $11 \beta$-hydroxysteroid dehydrogenase activity but because of its non-selective behaviour, it cannot be used in therapy. However, the structure of $18 \beta$-glycyrrhetinic acid may serve as a lead in the chemical synthesis of new and selective 11ß-HSD1 blockers.

Previously, we successfully purified 11ß-HSD1 in an active state from human and mouse liver microsomes (Maser and Bannenberg, 1994; Maser et al., 2002). Furthermore, we produced recombinant human 11 $\beta$-HSD1 enzyme by overexpression of the corresponding gene in E. coli and P. pastoris (Maser and Bannenberg, 1994; Blum et al., 2000; Maser et al., 2002). In the present investigation, we performed studies on potential and selective $11 \beta$ HSD1 inhibitors. We present new compounds with an oleanan or ursan scaffold which selectively inhibit $11 \beta$-HSD1 in the nM range, whereas $11 \beta$-HSD2 activity is affected only in $\mu \mathrm{M}$ concentrations of the inhibitor. Furthermore, we discuss the structural determinants that confer $11 \beta$-HSD1 specificity to these compounds and show new approaches to synthesize selective $11 \beta$-HSD1 inhibitors with an oleanan or ursan scaffold. Selective $11 \beta$-HSD1 inhibitors with an oleanan or ursan scaffold should have the advantage of low toxicity, the possibility of straightforward modifications of the scaffold to influence pharmacokinetic and pharmacodynamic properties, and sufficient resources in nature to get enough starting material. 


\section{Experimental}

\subsection{Preparation of biological fractions}

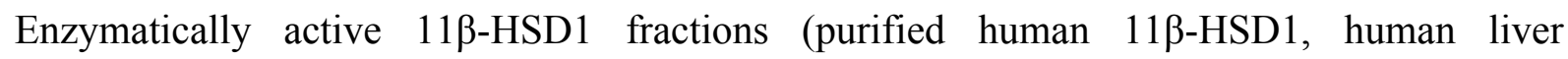
microsomes, as well as recombinant $11 \beta$-HSD1 overexpressed in E. coli and P. pastoris) were prepared as previously described (Blum et al., 2000; Maser et al., 2002). Human placental microsomes containing $11 \beta$-HSD2 were prepared as follows: The placenta samples were homogenized in 4 volumes of homogenization buffer $(20 \mathrm{mM}$ Tris/ $\mathrm{HCl}, 250 \mathrm{mM}$ sucrose, 1 mM EDTA, 0.1 mM PMSF, pH 7.4) using a glass-Teflon Potter-Elvehjem homogenizer. The homogenate was centrifuged at $600 \mathrm{xg}$ for $10 \mathrm{~min}$ and at $10000 \mathrm{xg}$ for $10 \mathrm{~min}$ to sediment nuclei, cell debris and mitochondria. The supernatant at this stage was centrifuged at 170.000 $\mathrm{x} \mathrm{g}$ for $1 \mathrm{~h}$ to sediment the microsomes. The microsomal pellet was resuspended in the homogenization buffer finally yielding a protein concentration of about $20 \mathrm{mg} / \mathrm{ml}$.

\subsection{Synthesis of selective 11 -HSD1 inhibitors.}

To elucidate the structural determinants of oleanan and ursan type triterpenes which confer $11 \beta$-HSD1 specific inhibition, a variety of pentacyclic triterpenes was prepared from $18 \beta$ glycyrrhetinic acid or other commercially available oleanan and ursan type triterpenes as starting material. The preparation was performed according to standard protocols of chemical synthesis and is described in detail under patent application PCT/DE 2007 / 002218.

\subsection{Enzyme Assays}

For analysis of $11 \beta$-HSD1 reductase inhibition the carbonyl reduction of cortisone to cortisol was measured. The assay performed contained an NADPH-regenerating system and was incubated for $3 \mathrm{~h}$ at $37^{\circ} \mathrm{C}$. For analysis of $11 \beta$-HSD1 dehydrogenase inhibition the oxidation of cortisol to cortisone was assayed in the presence of NADP and an incubation time of 60 min. Inhibition experiments were performed with human liver microsomes containing $11 \beta$ HSD1, with microsomes isolated from $P$. pastoris strains expressing recombinant human $11 \beta-$ HSD1, and with purified 11 $\beta$-HSD1 from human liver. For 11 $\beta$-HSD2 inhibition experiments human placental microsomes were used. The assay conditions for $11 \beta$-HSD2 inhibition

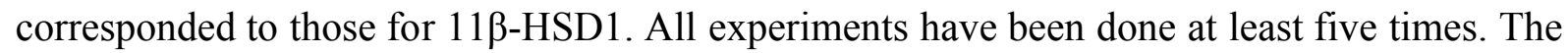
inhibition experiments of $11 \beta$-HSD1 activity, using different $11 \beta$-HSD1 preparations, resulted in similar inhibition pattern. The glucocorticoid concentration in the assays was $2 \mu \mathrm{M}$. 


\subsection{Docking simulations}

For all docking calculations we used the crystal structure of $11 \beta$-HSD type 1 available at the Protein Data Bank (PDB) (Berman et al., 2000) in complex with carbenoxolone (PDB code 2bel). The protein structure was treated with the protein preparation wizard in Maestro (Maestro, 2007) whilst the simulations were performed using Glide (Glide, 2007), both from the Schrödinger suite of programs. The ligands dataset was manually built in Maestro. During the protein preparation all water molecules were removed, hydrogen atoms were added and the complex was energy minimised using the default settings. The enclosing docking box, whose size in each direction was $27.5 \AA$, was centred on the nicotinamide $\mathrm{C} 4$ atom. The docking runs were performed in Standard Precision (SP) mode and in order to soften the potential for non polar parts of the ligands, the van der Walls radii of ligand atoms with partial atomic charge less than 0.15 were scaled by 0.8 . Only the top 5 energy ranked poses were retained and energy minimised for each studied compound: The top scoring conformer for each ligand was identified on the basis of the Emodel score whilst the subsequent comparison between different compounds was performed taking into account their corresponding Gscore values (this is a recommended procedure in Glide).

\section{Results and Discussion}

Some triterpenoids like carbenoxolone, dexamethasone or glycyrrethinic acid are already known to inhibit $11 \beta$-HSD1 but their use in therapy is limited by the fact that they block the activity of $11 \beta$-HSD2 as well, thereby provoking renal mineralocorticoid excess at higher dosage (Stewart et al., 1987; Walker et al., 1995; Walker and Seck1, 2003). Clinical interest in pentacyclic ursan and oleanan type triterpenes relate to their anti-inflammatory, anti-viral, apoptosis inducing and hypoglycemic properties, although the underlying mechanism in most cases is still unknown (Bühler et al., 1991; Matsuda et al., 1998). Corosolic acid, an ursan type triterpene isolated from the leaf of Banaba (Lagerstroemia speciosa), a traditional oriental medicine to treat diabetes, induces GLUT4 translocation and lowers plasma insulin levels in KK-Ay mice (Miura et al., 2004). Oleanoic acid, an oleanan type triterpene found in many plants with hypoglycemic activity e.g. M. charantia, G. sylvestre, exhibits the hypoglycemic activity on oral glucose-loaded rats by decreasing the rate of gastric emptying and inhibiting the glucose transport system at the small intestinal brush border (Matsuda et al., 1998). 
$18 \beta$-Glycyrrhetinic acid, an oleanan type triterpene and principal active ingredient of liquorice root, as well as its hemisuccinyl derivate carbenoxolone are potent inhibitors of $11 \beta$-HSD activity (Stewart et al., 1987; Hult et al., 2006), but display poor selectivity towards the two isoforms. Carbenoxolone has earlier been demonstrated to improve insulin sensitivity and to decrease glucose production in healthy human volunteers, but the $11 \beta$-HSD2 inhibitory activity of carbenoxolone was a limiting factor because it induces renal mineralocorticoid excess at higher dosis (Walker et al., 1995). By using 18ß-glycyrrhetinic as a lead structure, we prepared a variety of pentacyclic triterpenes from or other commercially available compounds (PCT/DE 2007 / 002218).

The results of our investigation emphasise the importance of a carbonyl group in 11-position of the pentacyclic scaffold for selective $11 \beta$-HSD1 recognition, whereas an acidic function in 20 -position is responsible for a strong, non-selective inhibition of both $11 \beta$-HSD isoenzymes (Fig. 2). Cleavage or masking of the acidic function of $18 \beta$-glycyrrhetinic acid resulted in selective $11 \beta$-HSD1 inhibition. Thereby, the selective inhibitory potency of the compound can be modulated by selection of the substituent in 20-position.

The comparison between oleanan and ursan triterpenes revealed that the methyl group in 19position of ursan type is accountable for a weak selective inhibition of $11 \beta-H S D 1$. The presence of a keto-function in 11-position enhanced the overall inhibition, whereas an acidic function in 4-position affects the recognition of the 11-keto-function by $11 \beta$-HSD1, resulting in high $\mathrm{IC}_{50}$ values (Fig .2).

In Fig. 3 the putative binding mode of the most selective compound of the series (Cpd04) is compared to carbenoxolone binding mode as found in the X-ray structure deposited at the PDB (PDB code 2bel). The inhibitor is stabilised in the binding cleft mainly by hydrophobic interactions. Moreover a hydrogen bond between the carbonyl group of the ligand and the hydroxyl group of a serine (S170) ensures further stabilisation (see Fig. 3B). Interestingly enough, experimental evidence shows that the non selective inhibitor carbenoxolone binds the enzyme in a similar fashion (see Fig. 3A). The condensed cycles of both inhibitors appear surrounded mainly by hydrophobic side chains while few polar interactions are established with the protein thanks to their carbonyl (Cpd04 and $\mathrm{CBO}$ ) and carboxyl (CBO) functional groups. Furthermore, as shown in Fig. 4, the good correlation found between experimentally obtained $\mathrm{pIC}_{50}$ values and calculated docking scores (Gscores), for the molecules in the dataset, highlights the robustness of the chosen docking method in producing reliable poses. All the compounds docked the protein in a similar way. 
Selective 11ß-HSD1 inhibitors that act in all tissues, particularly in adipocytes and skeletal muscles, have considerable potential as a drug directed against glucocorticoid related metabolic disorders. In particular, these inhibitors will improve insulin sensitivity and glucose uptake, reduce lipolysis, and counteract accumulation of visceral fat and its related metabolic

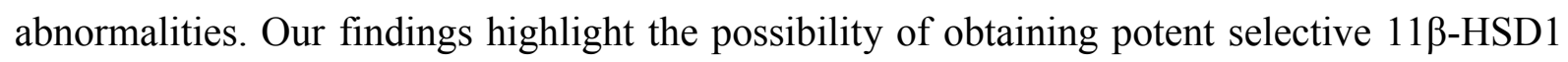
inhibitors based on the triterpene scaffold of the oleanan and ursan types. Selective 11 $\beta$-HSD1 inhibitors, based on those moieties, should have the advantage of low toxicity, the possibility of operating modifications of the scaffold to influence pharmacokinetic and pharmacodynamic properties, and sufficient resources in nature to get enough starting material. Finally, the good correlation between experimental data and docking calculations is currently used to design more potent and selective 11 $\beta$-HSD1 inhibitors. 


\section{Legends to the Figures}

Fig.1.

Ursan and oleanan type triterpenes.

Fig. 2.

Inhibition of $11 \beta$-HSD1 and $11 \beta-H S D 2$ by various ursan and oleanan type triterpenoids. For 11ß-HSD1, glucocorticoid oxidation (Ox.) and reduction (Red.) was measured. For 11ßHSD2, cortisol oxidation was assayed. Inhibition constants are given as $\mathrm{IC}_{50}$ values. Experiments have been repeated at least 5 times; n.d. $=$ not detectable. For details see Experimental section.

Fig. 3.

Carbenoxolone (CBO) at the $11 \beta-H S D 1$ active site $(\mathrm{A})$, as it appears in the X-ray structure available at the PDB (pdb code 2bel), compared to Cpd04 estimated binding pose (B). Residues S170, Y183, NADPH cofactor, carbenoxolone and Cpd04 are highlighted as dark grey and yellow coloured stick models, respectively. The dashed lines are drawn between atoms likely involved in $\mathrm{H}$-bond interactions.

Fig. 4.

Plot of observed $\mathrm{pIC}_{50}$ values $\left(11 \beta-H S D 1_{\text {Red. }}\right)$ versus docking scores (Gscore values obtained from Glide). The two compounds whose inhibitory potencies were not detectable were not included in the plot.

\section{Reference List}

Berman, H.M., Westbrook, J., Feng, Z., Gilliland, G., Bhat, T.N., Weissig, H., Shindyalov, I.N., Bourne, P.E., 2000. The Protein Data Bank. Nucleic Acids Res. 28, 235-242.

Blum, A., Martin, H., Maser, E., 2000. Human 11beta-hydroxysteroid dehydrogenase 1/carbonyl reductase: recombinant expression in the yeast Pichia pastoris and Escherichia coli. Toxicology 144, 113-120. 
Bühler, H., Perschel, F.H., Hierholzer, K., 1991. Inhibition of rat renal 11 $\beta$-hydroxysteroid dehydrogenase by steroidal compounds and triterpenoids; structure/function relationship. Biochim. Biophys. Acta 1075, 206-212.

Glide 2007. Version 4.5, New York, NY: LLC.

Hughes, K.A., Webster, S.P., Walker, B.R., 2008. 11-Beta-hydroxysteroid dehydrogenase type 1 (11beta-HSD1) inhibitors in type 2 diabetes mellitus and obesity. Expert. Opin. Investig. Drugs 17, 481-496.

Hult, M., Shafqat, N., Elleby, B., Mitschke, D., Svensson, S., Forsgren, M., Barf, T., Vallgarda, J., Abrahmsen, L., Oppermann, U., 2006. Active site variability of type 1 11 beta-hydroxysteroid dehydrogenase revealed by selective inhibitors and cross-species comparisons. Mol. Cell. Endocrinol. 248, 26-33.

Kim, D.H., Yu, K.W., Bae, E.A., Park, H.J., Choi, J.W., 1998. Metabolism of kalopanaxsaponin $\mathrm{B}$ and $\mathrm{H}$ by human intestinal bacteria and antidiabetic activity of their metabolites. Biol. Pharm. Bull. 21, 360-365.

Kotelevtsev, Y. et al., 1997. 11ß-Hydroxysteroid dehydrogenase type 1 knockout mice show attenuated glucocorticoid-inducible responses and resist hyperglycemia on obesity or stress. Proc. Natl. Acad. Sci. U. S. A. 94, 14924-14929.

Liu, Y., Nakagawa, Y., Wang, Y., Li, R., Li, X., Ohzeki, T., Friedman, T.C., 2003. Leptin activation of corticosterone production in hepatocytes may contribute to the reversal of obesity and hyperglycemia in leptin-deficient ob/ob mice. Diabetes 52, 1409-1416.

Livingstone, D.E., Jones, G.C., Smith, K., Jamieson, P.M., Andrew, R., Kenyon, C.J., Walker, B.R., 2000. Understanding the role of glucocorticoids in obesity: tissue-specific alterations of corticosterone metabolism in obese Zucker rats. Endocrinology 141, 560563.

Maestro 2007. Version 8, New York, NY: LLC.

Maser, E., Bannenberg, G., 1994. The purification of 11 $\beta$-hydroxysteroid dehydrogenase from mouse liver microsomes. J. Steroid Biochem. Molec. Biol. 48, 257-263. 
Maser, E., Volker, B., Friebertshauser, J., 2002. 11 Beta-hydroxysteroid dehydrogenase type 1 from human liver: dimerization and enzyme cooperativity support its postulated role as glucocorticoid reductase. Biochemistry 41, 2459-2465.

Masuzaki, H., Paterson, J., Shinyama, H., Morton, N.M., Mullins, J.J., Seckl, J.R., Flier, J.S., 2001. A transgenic model of visceral obesity and the metabolic syndrome. Science 294, 2166-2170.

Masuzaki, H. et al., 2003. Transgenic amplification of glucocorticoid action in adipose tissue causes high blood pressure in mice. J. Clin. Invest. 112, 83-90.

Matsuda, H., Li, Y., Murakami, T., Matsumura, N., Yamahara, J., Yoshikawa, M., 1998. Antidiabetic principles of natural medicines. III. Structure-related inhibitory activity and action mode of oleanolic acid glycosides on hypoglycemic activity. Chem. Pharm. Bull. (Tokyo) 46, 1399-1403.

Miura, T., Itoh, Y., Kaneko, T., Ueda, N., Ishida, T., Fukushima, M., Matsuyama, F., Seino, Y., 2004. Corosolic acid induces GLUT4 translocation in genetically type 2 diabetic mice. Biol. Pharm. Bull. 27, 1103-1105.

Morton, N.M., Holmes, M.C., Fievet, C., Staels, B., Tailleux, A., Mullins, J.J., Seck1, J.R., 2001. Improved lipid and lipoprotein profile, hepatic insulin sensitivity, and glucose tolerance in 11beta-hydroxysteroid dehydrogenase type 1 null mice. J. Biol. Chem. 276, 41293-41300.

Murakami, T., Emoto, A., Matsuda, H., Yoshikawa, M., 2001. Medicinal foodstuffs. XXI. Structures of new cucurbitane-type triterpene glycosides, goyaglycosides-a, -b, -c, -d, e, -f, -g, and -h, and new oleanane-type triterpene saponins, goyasaponins I, II, and III, from the fresh fruit of Japanese Momordica charantia L. Chem. Pharm. Bull. (Tokyo) $49,54-63$.

Sandeep, T.C., Yau, J.L., MacLullich, A.M., Noble, J., Deary, I.J., Walker, B.R., Seckl, J.R., 2004. 11Beta-hydroxysteroid dehydrogenase inhibition improves cognitive function in healthy elderly men and type 2 diabetics. Proc. Natl. Acad. Sci. U. S. A. 101, 67346739.

Seckl, J.R., 2004. 11beta-hydroxysteroid dehydrogenases: changing glucocorticoid action. Curr. Opin. Pharmacol. 4, 597-602. 
Shimizu, K., Ozeki, M., Tanaka, K., Itoh, K., Nakajyo, S., Urakawa, N., Atsuchi, M., 1997. Suppression of glucose absorption by extracts from the leaves of Gymnema inodorum. J. Vet. Med. Sci. 59, 753-757.

Stewart, P.M., Valentino, R., Wallace, A.M., Burt, D., Shackleton, C.H.L., Edwards, C.R.W., 1987. Mineralocorticoid activity of liquorice: 11 beta-hydroxysteroid dehydrogenase deficiency comes of age. Lancet ii, 821-824.

Walker, B.R., Connacher, A.A., Lindsay, R.M., Webb, D.J., Edwards, C.R., 1995. Carbenoxolone increases hepatic insulin sensitivity in man: a novel role for 11oxosteroid reductase in enhancing glucocorticoid receptor activation. J. Clin. Endocrinol. Metab. 80, 3155-3159.

Walker, B.R., Seck1, J.R., 2003. 11beta-hydroxysteroid dehydrogenase type 1 as a novel therapeutic target in metabolic and neurodegenerative disease. Expert. Opin. Ther. Targets. 7, 771-783.

Yoshikawa, M., Murakami, T., Matsuda, H., 1997. Medicinal foodstuffs. X. Structures of new triterpene glycosides, gymnemosides-c, -d, -e, and -f, from the leaves of Gymnema sylvestre R. Br.: influence of gymnema glycosides on glucose uptake in rat small intestinal fragments. Chem. Pharm. Bull. (Tokyo) 45, 2034-2038. 
Fig: 1

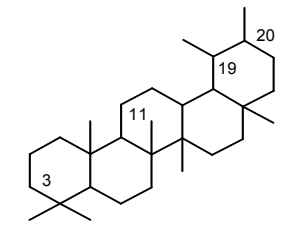

Ursan

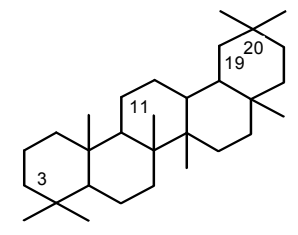

Oleanan

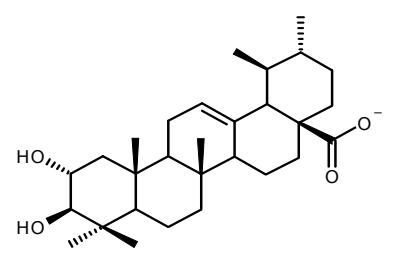

Corosolic acid

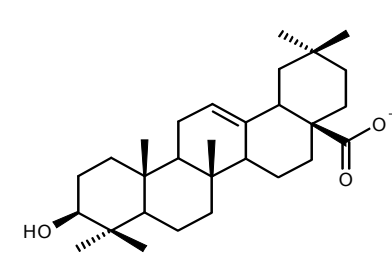

Oleanoic acid

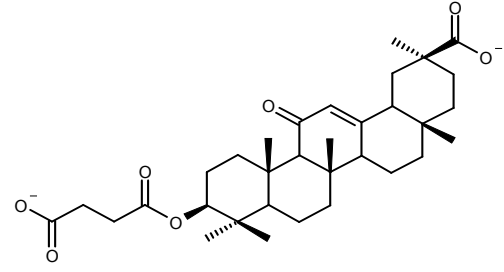

Carbenoxolone 
Fig. 2

\begin{tabular}{|c|c|c|c|c|}
\hline Id & Sketch & $\begin{array}{c}11 \beta-H S D 1_{\text {ox. }} \\
\left(\mathrm{IC}_{50}\right)\end{array}$ & $\begin{array}{c}11 \beta-H S D 1_{\text {Red. }} \\
\left(\mathrm{IC}_{50}\right)\end{array}$ & 11ß-HSD2 \\
\hline Cpd01 & & $12 \mathrm{nM}$ & $12 \mathrm{nM}$ & $8 \mathrm{nM}$ \\
\hline Cpd02 & & $>200 \mu \mathrm{M}$ & n.d. & n.d. \\
\hline Cpd03 & & $1 \mu \mathrm{M}$ & $68 \mu \mathrm{M}$ & n.d. \\
\hline Cpd04 & & $56 \mathrm{nM}$ & $244 \mathrm{nM}$ & $12 \mu \mathrm{M}$ \\
\hline Cpd05 & & $49 \mathrm{nM}$ & $149 \mathrm{nM}$ & $16 \mu \mathrm{M}$ \\
\hline Cpd06 & & $177 \mathrm{nM}$ & $122 \mathrm{nM}$ & $25 \mu \mathrm{M}$ \\
\hline Cpd07 & & $74 \mathrm{nM}$ & $124 \mathrm{nM}$ & $16 \mu \mathrm{M}$ \\
\hline Cpd08 & & $61 \mathrm{nM}$ & $119 \mathrm{nM}$ & $>200 \mu \mathrm{M}$ \\
\hline Cpd09 & & $68 \mathrm{nM}$ & $141 \mathrm{nM}$ & $>200 \mu \mathrm{M}$ \\
\hline Cpd10 & & $2 \mu \mathrm{M}$ & $39 \mu \mathrm{M}$ & $>200 \mu \mathrm{M}$ \\
\hline Cpd11 & & $2 \mu \mathrm{M}$ & $37 \mu \mathrm{M}$ & $>200 \mu \mathrm{M}$ \\
\hline Cpd12 & & $9 \mu \mathrm{M}$ & $>200 \mu \mathrm{M}$ & n.d. \\
\hline Cpd13 & & $11 \mu \mathrm{M}$ & $74 \mu \mathrm{M}$ & n.d. \\
\hline Cpd14 & & $5 \mu \mathrm{M}$ & $>200 \mu \mathrm{M}$ & n.d. \\
\hline Cpd15 & & $3 \mu \mathrm{M}$ & $112 \mu \mathrm{M}$ & n.d. \\
\hline Cpd16 & & n.d. & n.d. & n.d. \\
\hline
\end{tabular}


Fig. 3
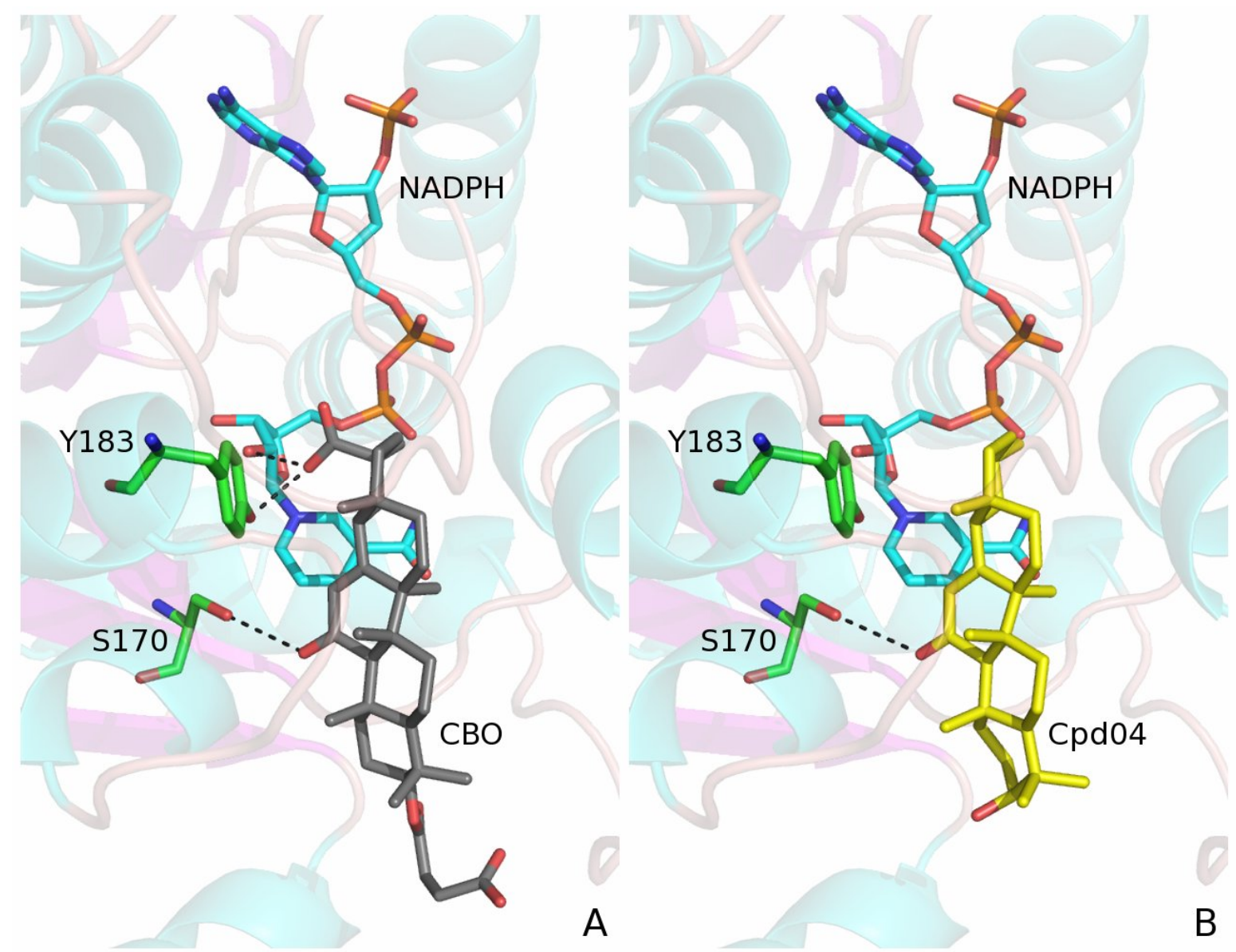
Fig. 4

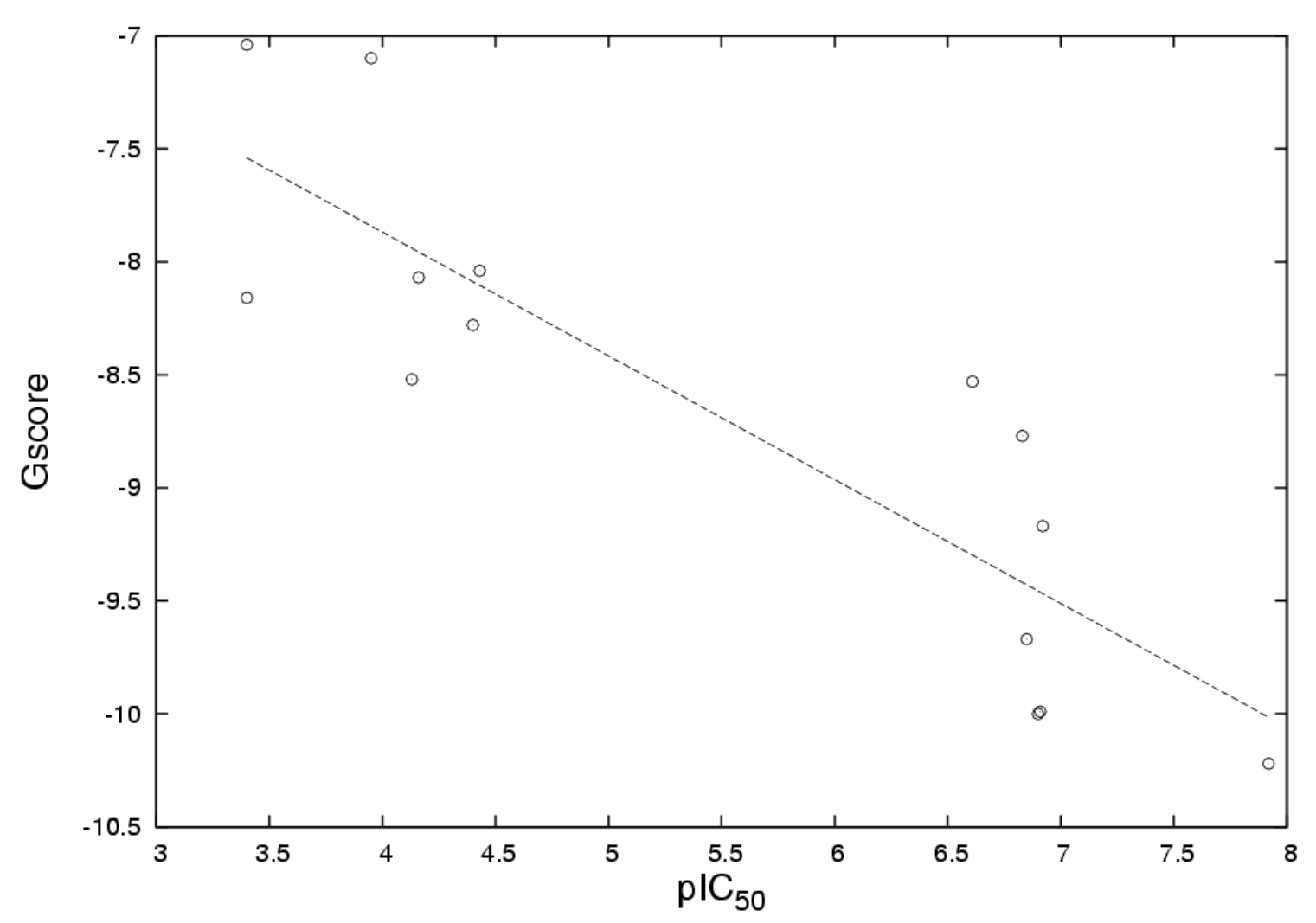

\begin{tabular}{|c|c|c|}
\hline Id & $\begin{array}{c}\text { pIC50 } \\
\text { Red. }\end{array}$ & Gscore \\
\hline Cpd01 & 7.920 & -10.22 \\
\hline Cpd08 & 6.924 & -9.17 \\
\hline Cpd06 & 6.914 & -9.99 \\
\hline Cpd07 & 6.907 & -10 \\
\hline Cpd09 & 6.852 & -9.67 \\
\hline Cpd05 & 6.827 & -8.77 \\
\hline Cpd04 & 6.613 & -8.53 \\
\hline Cpd11 & 4.432 & -8.04 \\
\hline $\mathrm{Cpd} 10$ & 4.409 & -8.28 \\
\hline $\mathrm{Cpd} 03$ & 4.167 & -8.07 \\
\hline $\mathrm{Cpd} 13$ & 4.131 & -8.52 \\
\hline $\mathrm{Cpd} 15$ & 3.951 & -7.1 \\
\hline $\mathrm{Cpd} 12$ & 3.398 & -8.16 \\
\hline $\mathrm{Cpd} 14$ & 3.398 & -7.04 \\
\hline
\end{tabular}

